\title{
Quality of Life Among Thalassemia Children Patients in the Gaza Strip
}

\author{
Yousef Ibrahim Aljeesh \\ College of Nursing, Islamic University of Gaza, Gaza Strip, Palestine
}

\section{Email address:}

yjeesh@iugaza.edu.ps

\section{To cite this article:}

Yousef Ibrahim Aljeesh. Quality of Life Among Thalassemia Children Patients in the Gaza Strip. American Journal of Nursing Science. Vol. 5, No. 3, 2016, pp. 106-113. doi: 10.11648/j.ajns.20160503.15

Received: May 16, 2016; Accepted: May 24, 2016; Published: June 4, 2016

\begin{abstract}
This study aimed to assess the quality of life of children (3-12 years) diagnosed with Thalassemia in Gaza Strip. A descriptive, analytical, cross-sectional design was used. All children 3-12 years old who were diagnosed with thalassemia and live in GS were included in the study (75 cases) with response rate $(81.3 \%)$. Participants were interviewed by the researcher and completed the questionnaire which focused on quality of life of chronic diseases and included five domains. These domains are physical health, psychological health, social relationships, environment health and personal safety. Validity and reliability of the instrument were tested and the total instrument reliability test (Cronbach's Alpha) was 0.767 . The scores for the study domains ranged between 2.81 for personal security domain and 3.66 for environmental health domain. Moreover, the study domains did not show statistically significant difference when compared by sex, living places, monthly income the relationship between parents and recurrent hospitalization. The findings of this study suggest the need of children diagnosed with thalassemia for support in all study domains. Health professionals need to work to minimize the disease's burdens. The current study calls the attention of health policy makers for new policies and new roles for the community health nurses and social workers. The study also revealed that there is a bad need to pay more attention when caring and dealing with thalassemia patients. Special food supplementation should be available in order to improve their physical health, more psychological support from their families and the society is needed. In addition, there is a need to provide safe environment and to enhance personal safety of these children.
\end{abstract}

Keywords: Chronic Diseases, Thalassemia, Quality of Life, Gaza Strip

\section{Introduction}

Thalassemia is considered one of the most common known hereditary blood disorders in mankind quantitatively affecting the synthesis of human hemoglobin. At least 60,000 severely affected individuals are born every year. Thalassemia has been encountered practically in every racial group and geographical location in the world. However, it is more common among individuals originating from tropical and subtropical regions [1] and it is considered a serious public health issues in the Mediterranean area [2].

Thalassemia is a chronic disease that poses a range of clinical and psychological challenges. It's implications on physical health can lead to physical deformity, under development and delayed puberty [3]. Moreover; heart failure, cardiac arrhythmia, liver disease, endocrine disease, and increased susceptibility to infection are common complications among children diagnosed with thalassemia [4].

Thalassemia International Federation disseminated that only about 200,000 patients with thalassemia major are alive and registered and receiving regular treatment around the world [5]. Thalassemia affects approximately 4.4 of every 10,000 live births throughout the world. It causes males and females to inherit the relevant gene mutations equally because it follows an autosomal pattern of inheritance with no preference for gender. Approximately 5\% of the worldwide population has a variation in the alpha or beta part of the hemoglobin molecule, although not all of these are symptomatic, and some are known as silent carriers. In fact, only $1.7 \%$ of the global population has signs as a result of the gene mutations; known as a thalassemia trait. All types of thalassemia can be fatal in some cases, particularly when there are multiple gene mutations that affect the production 
of the globin chains. In 2013, 25,000 deaths were attributable to thalassemia, which revealed a significant improvement when compared with the 36,000 deaths recorded in 1990 [6].

Although Palestine is one of the Mediterranean basin countries in which thalassemia is prevalent, a few number of studies had been carried out on the disease [7]. The occurrence of hereditary hemochromatosis among $\beta$ thalassemia intermediate and $\beta$-thalassemia minor subjects in the Gaza Strip (GS) was assessed by Harara [8]. The overall prevalence of $\beta$-thalassemia in the GS was $4.3 \%$ [9]. In GS, Palestine $0.02 \%$ of the population has been identified as $\beta$ thalassemia major [7].

Thalassemia is considered an exhausting, patient suffering disease from two aspects; the chronic nature of the disease itself in terms of frequent hospital visits, drug availability, side effects of drugs and disease complications [1, 2] implications of the disease on the quality of life (QOL) of patients regarding the physical, psychological, emotional, and social aspects [10].

Although $\alpha$ - and $\beta$-thalassemia are the most common types of thalassemia, the most important genetic variety of thalassemia is $\beta$-thalassemia which is caused by impaired production of $\beta$-globin chain types, causing severe transfusiondependent anemia, which significantly leads to poor QOL [11].

QOL involves components of happiness, satisfaction with life and how people feel about life conditions. There is a wide range of QOL domains depending on the context and scientific disciplines. For example, in health-related professions, the focus is on health-related QOL [12], in philosophy, the focus is on the good life, in economic science, the focus is welfare and distribution, in social science, the focus is objective and subjective well-being [13], and in psychology, the focus is psychological well-being. Nonetheless, few studies have evaluated the QOL of children diagnosed with thalassemia [14], particularly performing ingroup comparisons with healthy children [15].

There are many QOL factors that cover the wide range of life domains such as; general health, physical health, safety, social well-being and functioning, recreational opportunities, emotional functioning, cognitive functioning, surrounding environment, existential issues, compensation and finance, and freedom of expression $[16,17]$.

Thalassemia can be fatal if proper treatment is not received. Over the past decades, the development of new treatments and clinical management have significantly enhanced the prognosis as well as the survival rates of the patients [18]. However, the positive effect of these treatments is likely to be diminished, especially in terms of QOL, if they interfere with daily activities or if they were less tolerable. This might be the case in regular blood transfusions that require repeated visits to the hospital, and nightly subcutaneous injections of iron chelation therapy [19]. QOL is an important indicator of health and well-being. It determines the effectiveness of treatment and helps in policy developments [20]. Furthermore, it is used for evaluating the overall well-being of individuals and communities.

QOL of children diagnosed with thalassemia was not fully acknowledged and it should bring attention and consideration of health care providers and decision makers.

In 2012, the number of adult-thalassemia children patients (more than 12 years) treated at Ministry of Health (MOH) hospitals in GS reached 311 patients, while the number of thalassemia children (12 years or less) reached 75 cases. Within the chronic uncertainty condition in GS and repeated shortage of drugs at $\mathrm{MOH}$ hospitals, 200 patients live under sustained psychological pressure and varying degrees of physical symptoms [21]. Many medical problems that result from thalassemia lead to a reduction in physical functioning and medical complications such as cardiovascular and neurological complications. Furthermore, evaluation of QOL of children diagnosed with thalassemia residing in GS has not been previously studied [10].

In GS there is an increasing number of thalassemia cases among unmarried individuals on account of several reasons, including the nature of the Palestinian society, which refuses to marry a thalassemia patient for fear of giving birth to babies carrying the disease. This is in addition to the Palestinian laws which prohibit marriage between patients carrying the genetic recipe of the disease until the blood test for thalassemia shows that the couples are free from the disease [10].

Bearing that in mind, the impact of thalassemia on QOL was not fully acknowledged and it should bring attention and consideration of health care providers and decision makers. Therefore, the researcher became motivated to conduct this study to determine the QOL among thalassemia children patients aged 3-12 years. The QOL was evaluated by using five dimensions: physical health, mental health, social relations, environmental health and personal safety.

\section{Methodology}

\subsection{Setting of the Study}

The study was conducted at the only specialized pediatric hospital in GS where a separate specialized unit is available to receive these patients and prepared for blood transfusion and administering injections of Iron chelation therapy (Desferal injection) at least twice monthly. All pediatric patients diagnosed with thalassemia in GS receives medical care at this hospital.

\subsection{The Sample}

All thalassemia children patients in GS between the age of three and 12 years old were included in this study ( 75 cases). The total number of children participated in this study was 61 (response rate $81.35 \%$ ).

\subsection{Study Design}

The design of this study is a descriptive, analytical, crosssectional design. This type of study is useful to gather information on important health-related aspects of participants' knowledge at a specific point of time. It is quick, cheap, easy to conduct, and it enables the researcher to meet the study objectives in a short time [22]. 


\subsection{Eligibility Criteria}

The study included all children between three and 12 years old who were diagnosed with thalassemia and live in GS. Of the total number of the target population, there were five patients traveling outside GS, therefore; the researcher could not reach to them. Besides that, there were another four patients who live in Rafah governorate and the researcher could not reach to them because there were no clear addresses or phone numbers available for them. Moreover, the parents of five patients refused to participate in the study.

\subsection{Study Instrument}

An interview questionnaire that was developed by the researcher was used in this study. The questionnaire consists of two parts. The first part includes demographic personal information such as: sex, age, place of living, monthly income, level of education and the relationship between parents. The second part was designed to explore participants' level of QOL. Items in this part reflected the five dimensions of quality of participants' life. This part consisted of 30 items designed to assess the different dimensions of QOL using a five-point Likert scale $(1=$ very little, $2=$ a little amount, $3=$ a moderate amount, $4=$ very much, $5=$ an extreme amount).

\subsection{Reliability and Validity of the Instrument}

To ensure the validity of the instrument, construct validity of each domain and total degree of the instrument was done by using correlation coefficient ( $\mathrm{r}$ 0.537-0.829, $\mathrm{p}$ value at 0.05). Small scale reliability coefficient and Cronbach's Alpha were done and the result was satisfactory ( $\mathrm{r}$ 0.767). Moreover; content validity ratio was conducted by five experts in the field to ensure relevance, clarity and completeness of the instrument. Few recommendations were made by the experts and were taken into consideration by the researcher so that the questionnaire would be easy to comprehend and simple to understand by the children population and their parents.

\subsection{Ethical Consideration and Procedures}

Ethical approval from the $\mathrm{MOH}$ and administrative approval from the General Directorate of hospitals were obtained. One of the parents of each participant signed a consent paper on behalf of his/her child to participate in the study and received an explanatory form about the study that was attached to the questionnaire. It includes a statement about patients' right to participate or to refuse to participate in the study. Ethical concepts, anonymity, right to withdraw at any time, and respect for opinions and perspectives for children and their parents were taken in consideration in this study.

\subsection{Data Collection}

Data were collected through a face-to-face interview with each participant and one of his/her parents. At the start, all questionnaire forms were prepared, organized, and classified with serial numbers to ensure the availability of the needed information. The patients and their parents were informed about the aims of the study and that participation would be voluntary.

\subsection{Data Analysis}

Data analysis was carried out by a statistician and the researcher. Means have been computed for the continuous numeric variables. To illustrate the main characteristics of the respondents, frequency tables have been used. Advanced statistical analysis was conducted to explore potential relationships between variables, student t-test and one way ANOVA test to examine potential relationships between the continuous variables. $r$ test and Cronbachs' alpha test were used to measure the construction of validity and reliability of the instrument. $\mathrm{P}$ values of $\leq 0.05$ was considered statistically significant.

\section{Results}

\subsection{Socio-demographic Characteristics of Participants}

A total of 61 children participated in this study. Table one summarizes the characteristics of the participants. The sample consisted of $32(52.5 \%)$ males and $29(47.5 \%)$ females. The majority of participants live in North Governorate $(42.6 \%)$ and Gaza Governorate (41\%). The monthly income of the majority of participants $(65.6 \%)$ was $\leq 1,000$ New Israeli Shekels (NIS) which is about \$256. 28 participants $(45.9 \%)$ inherited thalassemia genes from both parents. Most of the participants $(62.3 \%)$ were hospitalized at some point during their illness.

Table 1. Socio-demographic data of the study population.

\begin{tabular}{|c|c|c|c|}
\hline Variables & Groups & Frequency & Percent \\
\hline \multirow{2}{*}{ Gender } & Male & 32 & $52.5 \%$ \\
\hline & Female & 29 & $47.5 \%$ \\
\hline \multirow{4}{*}{ Living place } & North Governorate & 26 & $42.6 \%$ \\
\hline & Gaza Governorate & 25 & $41.0 \%$ \\
\hline & $\begin{array}{l}\text { Mid Zone } \\
\text { Governorate }\end{array}$ & 8 & $13.1 \%$ \\
\hline & $\begin{array}{l}\text { Khan Younis } \\
\text { Governorate }\end{array}$ & 2 & $3.3 \%$ \\
\hline \multirow{3}{*}{ Monthly income } & Up to 1000 NIS & 6 & $65.6 \%$ \\
\hline & 1001 to 2000 NIS & 15 & $24.6 \%$ \\
\hline & More than 2000 NIS & 40 & $9.8 \%$ \\
\hline \multirow{4}{*}{$\begin{array}{l}\text { Child inherited the } \\
\text { thalassemia gene }\end{array}$} & From father side & 10 & $16.4 \%$ \\
\hline & From mother side & 9 & $14.8 \%$ \\
\hline & $\begin{array}{l}\text { From both parents } \\
\text { side }\end{array}$ & 28 & $45.9 \%$ \\
\hline & $\begin{array}{l}\text { No relationship } \\
\text { between parents }\end{array}$ & 14 & $23.0 \%$ \\
\hline \multirow{2}{*}{ Hospitalization } & yes & 38 & $62.3 \%$ \\
\hline & No. & 23 & $37.7 \%$ \\
\hline
\end{tabular}




\subsection{Quality of Life of Children Diagnosed with Thalassemia}

The general QOL scale used in this study included five domains: physical health, psychological health, social relationships, environmental health, and personal security.
Table two exhibits the mean score and standard deviation for each scale and its subdomains for the participants of this study. The environmental health domain received the highest mean score (3.66) while the personal security domain received the least mean score (2.81).

Table 2. Scores of QOL Domains.

\begin{tabular}{|c|c|c|}
\hline Item & Means & S. D \\
\hline Physical Health Domain & 3.62 & 1.15 \\
\hline I feel active daily and I play frequently in my region and school & 3.82 & 0.92 \\
\hline Physical pain prevents me from doing my works and homework's & 3.38 & 1.17 \\
\hline I find difficulties in sleep & 3.34 & 1.38 \\
\hline I feel with fatigue & 2.72 & 1.16 \\
\hline I eat abnormal amount of food (large or little) & 3.03 & 1.12 \\
\hline Psychological Health Domain & 3.51 & 1.27 \\
\hline I am satisfied about my myself & 3.72 & 1.23 \\
\hline I feel with happiness and pleasure & 3.70 & 1.15 \\
\hline Through the last weeks I suffered from fear, sadness, anxiety, blue mood & 2.95 & 1.26 \\
\hline I perform my homework that needs understanding and thinking quickly & 3.51 & 1.18 \\
\hline I forget lots of things & 3.46 & 1.22 \\
\hline I feel that life is beautiful and interesting & 3.61 & 1.08 \\
\hline In the night, I dream with disturbing things and nightmare & 3.60 & 1.36 \\
\hline Social Relationships Domain & 3.53 & 1.35 \\
\hline I make friends in my region and school & 3.56 & 1.34 \\
\hline I like to be with friends and colleagues & 3.77 & 1.27 \\
\hline I prefer to stay in my home & 3.16 & 1.38 \\
\hline I can easily make friendly relationships with others & 3.70 & 1.33 \\
\hline I prefer to be alone most the time & 3.23 & 1.51 \\
\hline I am comfortable when I am with my friends & 3.75 & 1.29 \\
\hline Environmental Health Domain & 3.66 & 1.22 \\
\hline All means of relaxation and playing are provided in the home and school & 3.66 & 1.29 \\
\hline I have time to practice my preferred games & 3.54 & 1.31 \\
\hline I take enough pocket money to meet my daily needs & 3.57 & 1.32 \\
\hline There is a place for plying & 3.46 & 1.18 \\
\hline Special needs for me are available in local shops & 3.70 & 1.15 \\
\hline My surrounding environment is clean & 4.08 & 1.07 \\
\hline I face difficulties in transportation when I go to the closed regions & 3.62 & 1.19 \\
\hline Personal Security Domain & 2.81 & 1.19 \\
\hline I feel safe at my home & 4.28 & 1.02 \\
\hline I feel peace in the roads & 3.28 & 1.34 \\
\hline I get frighten with a loud voice & 2.52 & 1.40 \\
\hline I suffer from anxiety when I alone & 2.44 & 1.30 \\
\hline I like to go out with one of my family & 1.52 & 0.87 \\
\hline
\end{tabular}

\subsection{Relationship Between Study Variables and QOL Dimensions}

The relationship among all domains of QOL included in the study and the demographic characteristics of participants (age, gender, place of living, monthly income, and hospitalization) were studied (table 3 ). Thalassemia children patients have near normal life activities and a life span close to others who are normal. 
Table 3. Relationship between all study variables and the study dimensions.

\begin{tabular}{|c|c|c|c|c|}
\hline Dimension & Variable & Groups & Mean & Overall quality "P value" \\
\hline Physical Health & Gender & $\begin{array}{l}\text { Male } \\
\text { Female }\end{array}$ & $\begin{array}{l}103.41 \\
99.79\end{array}$ & 0.356 \\
\hline Psychological Health & Living place & $\begin{array}{l}\text { North G } \\
\text { Gaza G. } \\
\text { Mid. G. } \\
\text { Khan younis G. }\end{array}$ & $\begin{array}{l}101.69 \\
102.64 \\
101.88 \\
89.00\end{array}$ & 0.691 \\
\hline Social relationships & Monthly income & $\begin{array}{l}\text { Up to } 1000 \text { NIS } \\
\text { Up to } 2000 \text { NIS } \\
\text { More than } 2000 \text { NIS }\end{array}$ & $\begin{array}{l}101.48 \\
100.27 \\
106.67\end{array}$ & 0.681 \\
\hline Environment health & Parents relationship & $\begin{array}{l}\text { From father side } \\
\text { From mother side } \\
\text { From both parents } \\
\text { No relationship }\end{array}$ & $\begin{array}{l}98.30 \\
101.89 \\
100.54 \\
106.29\end{array}$ & 0.592 \\
\hline Personal safety & Hospitalization & $\begin{array}{l}\text { Yes } \\
\text { No }\end{array}$ & $\begin{array}{l}100.61 \\
103.48 \\
\end{array}$ & 0.477 \\
\hline
\end{tabular}

$P$ value is significant $\leq 0.05$

\section{Discussion}

Researchers in studies [11,23] attribute the abnormality of life activities and a life span to thalassemia children to iron overload which is considered the most important complication of blood transfusion in $\beta$-thalassemia patients.

From his experience, the researcher noticed that iron chelation therapy is still unsatisfactory in the GS. Some studies revealed that many patients suffer from very severe iron overload and most of them (86.8\%) are mainly chelated through subcutaneous pumps or intramuscular injection. This therapeutic method is not preferred by patients who find it painful and uncomfortable. In addition, the pumps are not always available or need continuous maintenance and repair. These children and their parents are hoping to switch to oral chelation therapy, assuming it is more comfortable and painless $[24,25]$.

This study was conducted to evaluate the level of quality of life for children between 3 to 12 years old who were diagnosed with thalassemia and live in Gaza Strip. A questionnaire that was developed by the researcher was used to evaluate their QOL. The results revealed low to moderate mean score for the five domains. Mean scores ranged between 2.81 (personal security domain) and 3.66 (environmental health domain).

\subsection{Physical Health Consistent}

The result of this study revealed that thalassemia isn't mainly affecting the physical health of patients. The researcher attributed this finding to the childhood and short time for adherence to treatment that may not affect physical health yet. The impact of thalassemia on physical health may become more evident as these children grow up and with the need for frequent hospitalizations and side effects of treatment and their impact on their activity of their daily living and work, which may negatively affect this domain of their QOL.

These results are consistent with the results of $[26,27]$ which revealed that the physical function had the lowest scores among all dimensions of their studies. Furthermore; other studies revealed that health-related QOL among patients with major/intermediate beta thalassemia is associated with poor physical health [28]. Such effect of thalassemia on physical health domain of QOL could be attributed to the implications of thalassemia and its treatment on physical health of patients and it can lead to physical deformity, under development and delayed puberty [3].

The results of this study revealed that there were no statically significant differences on the domain of physical health between male and female children diagnosed with thalassemia. This result is inconsistent with [26] who conducted a cross sectional study to evaluate the QOL in thalassemia children patients in Iran. Their findings showed that female participants had a higher score in all domains except for bodily pain when compared to the male participants. Such a difference was only significant in physical function and general health domains $(\mathrm{p}<0.05)$.

\subsection{Psychological Health}

Thalassemia patients are subject to multiple psychological stresses and may be threatened by many potential losses and lifestyle changes. Thalassemia is a chronic disease that poses a range of clinical and psychological challenges. Pain in patients with thalassemia disease is a problem of high importance as it affects the psychological health of the patients and prevents them to proceed normally in their lives [10].

Study results revealed that socio-demographic characteristics did not impact level of QOL including psychological domain. These findings were inconsistent with Gharaibeh, Amarneh [29] results that revealed a significant association between socio-demographic characteristics such as age, gender, school grade, current schooling, work, family income, and the occurrence of complications with the psychosocial burden variables.

Depression is associated with both poor physical and mental health related quality of life among patients with major/intermedia beta thalassemia, however somatic comorbidities and anxiety are associated with poor physical 
and mental health related quality of life, respectively [28]. Therefore, beta-thalassemia major patients are at risk for psychiatric symptomatology and need appropriate psychiatric consults [30].

\subsection{Social Relationship}

Children participated in this study reported moderate score (3.53) on the social relationship domain of QOL. Social and school functioning in thalassemia patients are not expected to match their counter partners healthy children. Many factors affect the social activities of children diagnosed with thalassemia. These factors include recurrent visits to hospitals, frequent blood transfusions and administration of desferral, iron overload complications and presence of pain. Presence of anemia triggers fatigue and getting tired easily which affects their ability to play with peers and making friend. Moreover; repeated hospitalizations and hospital visits will lead to frequent absenteeism from school, which will impact their educational performance and social relationships. For example, iron chelation therapy was found to have a significant negative effect in the school functioning subscale [2]. The QOL of thalassemia children are affected by multiple factors, such as family income and a family history of thalassemia. Supportive measures could improve the QOL in thalassemia children patients [29].

\subsection{Environmental Health}

Participants of this study rated the environmental health domain as the highest domain with a score of 3.66. These findings revealed that patients and their families can adapt to the disease burden and can live a near normal life as others; they go to school and perform their homework, play with peers and go to tourism. This result is inconsistent with the study of Safizadeh and Farahmandinia [26] which revealed that the lowest score by their participants was for the school domain.

The researcher indicated that the score for school functioning domain in thalassemia patients was significantly lower than those in control group of healthy children [31]. Such results should call the attention of healthcare providers, counsellors and school teachers about their important role in helping children to overcome this problem.

\subsection{Personal Safety}

Findings of this study revealed that thalassemia children have near normal life activities and life span compared with normal others. This result is consistent with [32] that revealed the availability of better transfusion regimen, iron chelation therapy, proper management of complications and good supportive care. This will help thalassemia patients to have a near normal life span with a good health related quality of life. As a result, attention has shifted to the wellbeing of the patients with thalassemia [33].

Findings of this study are not congruent with [34] study which illustrated that children with chronic diseases and their families face many difficulties as a result of the disease, leading to disruption in behavior such as aggression and the slow progress in their study, anxiety, depression, delay in the development of physical and nervous system, and increased fear and insecurity.

Also, findings were not confirmed by a study conducted by Abdellatif [35] that conducted to identify the problems of personal, social and economic development of dialysis children. This study found that dialysis children do not have the ability to form social relationships and they suffer from some personal problems such as anger, stubbornness, negative isolation, jealousy and sensitivity.

Furthermore, findings were not confirmed by a study of [36] that revealed thalassemia has a great negative impact on the wellbeing of the patients. Preserving good health related QOL is one of the major targets in clinical management of thalassemia patients

\section{Recommendations}

The findings of this study suggest that health care providers must provide a bio-psychosocial support for children with thalassemia, and encourage families to assist in providing support for the affected children.

The current study triggered the need for new policies and new roles for the community health nurses, social workers and other health care providers as well as the need for counseling and educational programs for children with thalassemia.

The results of this study can contribute to the development of a screening program for decreasing depression burden and promoting quality of life for children diagnosed with thalassemia and their parents.

The immense national cost of medical care and the tremendous psychosocial burdens on the patients and their families indicate the urgent need for clinical promotion through patient educational programs and counseling for these families.

\section{Conclusion}

This study aimed to assess the quality of life of children diagnosed with thalassemia in Gaza Strip. All children 3-12 years old who were diagnosed with thalassemia and live in GS were included in the study. Scores for the domains of QOL were relatively low and range between 2.81 for personal security domain and 3.66 for environmental health domain. Moreover, the study domains did not show statistically significant difference when compared sociodemographic characteristics of participants. The findings of this study suggest the need for support in all study domains for children diagnosed with thalassemia to minimize the disease burden. The current study calls the attention of health policy makers for new policies and new roles for health care professionals to improve the QOL of this vulnerable group of patients.

Chan TW \& Koo A. (2011): Parenting style and youth outcomes in the UK. European Sociological Review; 27 (3): 385-399. 


\section{References}

[1] Higgs DR, Engel JD, Stamatoyannopoulos G. (2012): Thalassaemia. The Lancet; 379(9813): 373-83.

[2] Thavorncharoensap M, Torcharus K, Nuchprayoon I, Riewpaiboon A, Indaratna K, Ubol B-o. (2010): Factors affecting health-related quality of life in Thai children with thalassemia. BMC Blood disorders; 10(1): 1.

[3] De Sanctis V, Roos M, Gasser T, Fortini M, Raiola G, Galati MC. (2006): Impact of long-term iron chelation therapy on growth and endocrine functions in thalassaemia. Journal of pediatric endocrinology \& metabolism: JPEM; 19(4): 471-80.

[4] Ghaffari J, Vahidshahi K, Kosaryan M, Parvinnejad N, Mahdavi M, Karami H. (2008): Nitroblue tetrazolium test in patients with beta-thalassemia major. Saudi medical journal; 29(11): 1601-5.

[5] Cappellini M-D, Cohen A, Eleftheriou A, Piga A, Porter J, Taher A. (2008): Guidelines for the clinical management of thalassaemia: Thalassaemia International Federation, Nicosia (CY).

[6] Bernadette. M, Matthew D. (2008): Global epidemiology of haemoglobin disorders and derived service indicators. Bulletin of the World Health Organization [Internet]. May, 07, 2015; 86(6): [417-96 pp.].

[7] Sirdah MM, Sievertsen J, Al-Yazji MS, Tarazi IS, Al-Haddad RM, Horstmann RD, et al. (2013): The spectrum of $\beta$ thalassemia mutations in Gaza Strip, Palestine. Blood Cells, Molecules, and Diseases; 50(4): 247-51.

[8] Harara Z. (2006): Occurrence of Hereditary Hemochromatosis Among $\beta$ - Thalassemia Intermediate and $\beta$-Thalassemia Minor Subjects in Gaza Stri -Palestine. Gaza, Palestine: Islamic University of Gaza.

[9] Sirdah M, Bilto YY, el Jabour S, Najjar K. (1998): Screening secondary school students in the Gaza strip for betathalassaemia trait. Clininical and Laboratory Haematology; 20(5): 279-83.

[10] Abu-Muammar A. (2015): Assessment of the Quality of Life among Thalassemia children patients in the Gaza Strip. Jerusalem, Palestine Al-Quds University.

[11] Cao A, Galanello R. (2010). Beta-thalassemia. Genetics in Medicine; 12(2): 61-76.

[12] Haberman M, Bush N, Young K, Sullivan KM, editors. (1992): Quality of life of adult long-term survivors of bone marrow transplantation: a qualitative analysis of narrative data. Oncology nursing forum.

[13] Berntsson LT, Kohler L. (2001): Quality of life among children aged 2-17 years in the five Nordic countries. The European Journal of Public Health; 11(4): 437-45.

[14] Garralda M, Jameson R, Reynolds J, Postlethwaite R. (1988): Psychiatric adjustment in children with chronic renal failure. Journal of Child Psychology and Psychiatry; 29(1): 79-90.

[15] Gerson AC, Riley A, Fivush BA, Pham N, Fiorenza J, Robertson J, et al. (2005): Assessing health status and health care utilization in adolescents with chronic kidney disease. Journal of the American Society of Nephrology; 16(5): 142732.
[16] Fayers P, Machin D. (2013): Quality of life: the assessment, analysis and interpretation of patient-reported outcomes: John Wiley \& Sons.

[17] Felce D, Perry J. (1995): Quality of life: Its definition and measurement. Research in developmental disabilities; 16(1): $51-74$.

[18] Borgna-Pignatti C, Rugolotto S, De Stefano P, Zhao H, Cappellini MD, Del Vecchio GC, et al. (2004): Survival and complications in patients with thalassemia major treated with transfusion and deferoxamine. haematologica; 89(10): 118793.

[19] Abetz L, Baladi J-F, Jones P, Rofail D. (2006): The impact of iron overload and its treatment on quality of life: results from a literature review. Health and Quality of Life Outcomes; 4(1): 1.

[20] Saban KL, Stroupe KT, Bryant FB, Reda DJ, Browning MM, Hynes DM. (2008): Comparison of health-related quality of life measures for chronic renal failure: quality of well-being scale, short-form-6D, and the kidney disease quality of life instrument. Quality of Life Research; 17(8): 1103-15.

[21] Ministry of Health. (2013): Health and Population Report. Gaza Strip, Palestine.

[22] Dawson B, Trapp RG. (2004): Basic \& clinical biostatistics. Basic \& clinical biostatistics: Lange Medical Books; McGraw-Hill.

[23] Youssef DM, Fawzy Mohammad F, Ahmed Fathy A, Aly Abdelbasset M. (2013): Assessment of Hepatic and Pancreatic Iron Overload in Pediatric Beta-Thalassemic Major Patients by Weighted Gradient Echo Magnetic Resonance Imaging. ISRN hematology.

[24] Wang C-H, Wu K-H, Tsai F-J, Peng C-T, Tsai C-H. (2006): Comparison of Oral and Subcutaneous Iron Chelation Therapies in the Prevention of Major Endocrinopathies in $\beta$ Thalassemia Major Patients. Hemoglobin; 30(2): 257-62.

[25] Neufeld EJ. (2006): Oral chelators deferasirox and deferiprone for transfusional iron overload in thalassemia major: new data, new questions. Blood; 107(9): 3436-41.

[26] Safizadeh H, Farahmandinia Z. (2012): Quality of life in patients with thalassemia major and intermedia in kerman-iran (IR). Mediterranean journal of hematology and infectious diseases; 4(1).

[27] Ayoub MD, Radi SA, Azab AM, Abulaban AA, Balkhoyor AH, Seif-eleslam WB, et al. (2013): Quality of life among children with beta-thalassemia major treated in Western Saudi Arabia. Saudi medical journal; 34(12): 1281-6.

[28] AzarKeyvan A, Hajibeigi B, Lankarani MM, Namdari M, Assaric S. (2009): Associates of poor physical and mental health-related quality of life in beta thalassemiamajor/intermedia. Journal of Research in Medical Sciences; 14(6): 349-55.

[29] Gharaibeh H, Amarneh BH, Zamzam SZ. (2009): The psychological burden of patients with beta thalassemia major in Syria. Pediatrics International; 51(5): 630-6.

[30] Majdi M, Marzabadi A. (2009): Quality of life in Iranian Beta-thalassemia major patients of southern coastwise of the Caspian Sea. International Journal of Behavioral Sciences; 2(4): 325-32. 
[31] Ismail A, Campbell MJ, Ibrahim HM, Jones GL. (2006): Health related quality of life in Malaysian children with thalassaemia. Health and Quality of life Outcomes; 4(1): 1.

[32] Dubey A, Parakh A, Dublish S. (2008): Current trends in the management of beta thalassemia. The Indian Journal of Pediatrics; 75(7): 739-43.

[33] Musallam K, Cappellini MD, Taher A. (2008): Challenges associated with prolonged survival of patients with thalassemia: transitioning from childhood to adulthood. Pediatrics; 121(5): e1426-e9.

[34] Roccella M, Leggio L, Parisi L, Turdo G, Testa D. (2005):
The quality of life in developing age subjects with chronic renal diseases. Minerva pediatrica; 57(3): 119-28.

[35] Abdellatif R. (1992): The Contribution of the Society in Organizing the Design of Social Welfare Programs for Children with Kidney Failure. The fifth scientific conference; Faculty of Social Work, University of Cairo, Fayoum.

[36] Pakbaz Z., Treadwell M, Ymashita R, Quirolo K, Foote D, Quill L, et al. (2005): Quality of life in patients with thalassemia intermedia compared to thalassemia major. Annals of the New York Academy of Sciences; 1054(1): 45761 . 